\title{
Online Search Engines Used By Undergraduate Students In Two Selected University In Ogun And Oyo States, Nigeria.
}

\author{
*Judith Odanwu Ogbole \\ (Library, University of Jos, Nigeria). \\ Corresponding Author: Judith Odanwu Ogbole
}

\begin{abstract}
The purpose of the study is to determine the types of Online search engines used by undergraduate students in Nigerian Universities. The sample comprised one hundred and fifty one (N-151) undergraduate students of two selected universities in Ogun and Oyo States. Data were collected from the participants with a self-structured validated questionnaire. Results were obtained through descriptive statistics of simple percentage, mean, standard deviation and ANOVA were used to test the formulated hypotheses at 0.005 significance level. The findings revealed that the most famous search engines were Google and yahoo. The study also revealed the major ways in which undergraduate students felt that improvement is required so as to increase knowledge of online search engines that includes reduction of information overload during browsing and also reduction in the cost of using search engines for students. Based on these findings, it was recommended that Librarians should provide knowledge about different online search engines to undergraduate students and not just Google and Yahoo through user education.
\end{abstract}

Keywords: Online search engines, Nigeria, university, undergraduate students, Web.

\section{Introduction}

The birth of the Internet has brought a great in the education sector globally and in Nigeria as well. This is because there is availability of search engines and other tools that aid teaching, research and learning. Usually, internet users prefer search engines to access required information from the internet because search engines are open for public use with billions of web sites and during last years, there are many important researches about this area. One of the main components of search engine is a robot which is known as Web Crawler (or Spider) and it works as a network surfer and downloads a searched web site to local disk. In the opinion of [1], web crawler is a kind of computer program that browses the Web in a methodical, automated way. This process is called Web Crawling or spidering. Search engines use spidering to provide up-to-date information. The most important aim of web crawler is copying all visited web pages for later searches to make next searches faster. Web crawlers can also used for automating maintenance task on a web site like checking links or validating code. [2] also affirmed that web crawlers are used to collect specific information from Web pages. Even web crawlers are very easy programs, they finds million of documents and helps to information retrieval systems to retrieve correct information in easy way. [3] added that Web crawler contains more of scientific journals, articles and also different scientists. Sometimes, crawler can help find the information which is hidden by website owner or webmaster. Because of this, many web crawlers has to work according to robots exclusion protocol. [3] stated that there are seven (7) major search engines. These are: Google, Google scholar, Bing, Yahoo, Blekko, Ask and Web crawler. The author further added that in using the major search engines, Google seems to be the most useful for online shopping, location and posting of articles on different subjects. Google scholar helps a researcher to search through, thousands of guaranteed scholarly articles and research reports being contains more of concepts. Yahoo(Yet another Hierarchical Officious Oracle) helps to get fast access to translation on institution. Blekko contains information on government sites, as well as different postal codes. Ask contains a lot of magazines, and also provide free social media sites. [4] defined a search engine as software of a computer that has the capability of searching through large volumes of text or other data for specified keywords, and then returning a list of files where the keywords are found. Just as there is cultural, political and geographical differences in the world's population, there are a number of search engines to fit the individual needs of every net citizen. According to [5], the World Wide Web offers access to information resources in many languages. Certain developments facilitate multilingual exploitation of these resources. Some search engines, for example, allow the user to restrict retrieved sites to those in particular languages; some also provide the searcher with an interface in a chosen language. Many web sites also offer their information in several languages, one of which typically is English. [6] study reveals that no one-search engine holds the key to ultimate search results. There are different search engines available [7] however, only a handful dominates in terms of usage [8]. Examples of 
search engines are DuckDuckgo, Google, Bing, yahoo, Ask.com, Kayak, AOLS, AltaVista. [9] stated that many search engines are equipped with multiple language support features; an indispensable translation feature is implemented in only a few search engines. Multiple language support features in search engines remain at the lexical level. It was found that the speed of search engine results has become a high priority to participants. [10] assert that search engine use has been found to be the second most popular Internet activity next to e-mail. Internet and the various search engines have brought information explosion. The information explosion may confuse students and other researchers on the information to use [11]. The web is a vital and fertile layer where new ideas continually lead to innovations - some good, some not [12]. While Google continues expanding and evolving, others persistently appear on the horizon with their own slant. Many undergraduate students do not use the vast number of online search engines because they do not know about them and how they function. [13] stated that lack of awareness of the various search engines, among undergraduate students in higher institution will bring to its non-usage.

The wide spread use of Web search engines, employment of simple queries, and decreased viewing of result pages may have resulted from algorithmic enhancements by Web search engine companies [16]. Search engines continue to attract a large number of Web searchers and consistently rank as some of the heavily visited sites in the market in terms of the number of visitors [17]. The need for users to find information as well as services available on the web is ever growing. Due to their tremendous economic value search engine companies constantly put major efforts to improve their search results. According to [18], user satisfaction with a particular search engine can only be measured using queries from the user's daily information needs and based on his/her personal assessment of utility of the returned results to the queries.

Undergraduate students use search engines for different purposes ranging from assignments, projects, entertainment, discussion forum, e-mailing among others. [14] assert that university students use the search engines for research and made evaluation on the quality and type of research materials being used. The authors maintained that students depend on giving the most positive ratings to sources that were easy to understand, easy to find and available. Most times, undergraduate students are required to search for information on their own. According to [15] dependence coupled with easy access to technology, points towards college students spending a substantial quantity of time on the search engine.

The reasons why a user might choose one search engine over another are complex but elements such as speed, popularity, home page style, relevantly ranked result fashion, simple language all play a vital role. Based on popularity, they have been clustering of traffic around a handful of extremely similar Web search engines such as Google and Yahoo. This approach is supported by statistics that show that Google and Yahoo! are some of the most talked about brands on the Web [19]. Reference [20] added that there are some factors which influence students in their preference of a search engine. These factors include homepage style, result page style, number of retrieved results, number of retrieved relevant results, popularity of search engines, and easy user interface. This paper aims to investigate types of online search engines used by undergraduate students' and their choice of preferences.

\subsection{Statement of the Problem}

The advent of web based technologies has brought a change in searching and finding of information among undergraduate students. The use of common search engines such as DuckDuckGo, Google, Bing, Yahoo, Ask.com, Alta Vista, AOLS, Kayak has increased exponentially the amount of data that individuals can have access and the sharing of information through platforms such as Wikipedia, as well as social media networks, effectively creates knowledge sharing communities. The online search engines therefore provide undergraduate students with the vital information they need to support their learning and also help to satisfy their information quest on daily basis. So many undergraduate students rely on search engines as their primary source of information.

However, most undergraduate students make use of few of the many vast number of online search engines as they are unaware and do not know the functionality of the search engines. Also, due to information overloading, irrelevant result display, poor network connectivity, and slow access speed these students spend a significant amount of time searching the web for vital information. This has led to only very few online search engines being used resulting in congestion of such heavily used ones. These raise the concern on how much of such information that is effectively retrieved and adequately utilized by undergraduate students in Federal University of Agriculture, Ogun State and University of Ibadan, Oyo State, Nigeria.

In response to these problems, this research proposes to determine several options for enabling undergraduate students have full knowledge of the vast number online search engines rather than rely on the few ones so as to achieve potential and maximum satisfaction that is needed from the use of search engines so as to achieve its enormous economic benefits. 


\subsection{Scope and limitation of the Study}

This research is restricted to undergraduate students of Federal university of Agriculture Abeokuta, Ogun State and University of Ibadan in Oyo State, Nigeria. The data obtained is from this category of target audience. One of the limitations of this research is that during the distribution of the questionnaire to the undergraduate students of the Federal University of Agriculture, Ogun State; not every undergraduate student was around to fil the questionnaire as expected because students were on partial break following an up rise.

\subsection{Significance of the Study}

The online search engines are computer based application tools that undergraduate students may use to find information on the Web. This study is significant because a better understanding of different types of online search engines outside the ones the students are used to would create awareness and help increase patronage in the number of search engines. This evidence-based study can help information programmers to work on the challenges encountered by undergraduate students when using the online search engines and this would lead to harnessing the potential goal of search engines. Findings from this study can be used as a stepping stone for further research on online search engines.

\subsection{Objectives}

\section{General Objective}

The emphasis of this study is on investigating the distinct types of online search engines and opinions of undergraduate students in their preference and challenges encountered when using search engines in two selected universities in Ogun and Oyo States, Nigeria.

The specific objectives are to:

i. Determine the various types of search engines use by undergraduate students.

ii. Assess the extent of usage of search engines by undergraduate students.

iii. Determine the purpose of use of search engines by undergraduate students.

iv. Determine the level of satisfaction derive from the use of search engines by undergraduate students.

v. Investigate the reasons that influence undergraduate students' likeness/preference for the use of search engines.

vi. Investigate the challenges encountered by undergraduate students when they use online search engines.

vii. Determine the ways of improving Search engines used by undergraduate students.

\subsection{Research Questions}

The study will provide answers to the following questions:

1) What are the various types of search engines use by undergraduate students?

2) What is the frequency of usage of Search engines among undergraduate students?

3) What is the purpose of use of Search engines by undergraduate students?

4) What is the level of satisfaction by students when they use Search engines?

5) What are the reasons for the choice/preference of Search engines used by undergraduate students?

6) What are the challenges encountered by undergraduate students?

7) What are the various ways of improving search engines by undergraduate students?

\subsection{Hypothesis}

Three hypotheses were formulated for this research:

Ho1: There is no significant difference between types of Online Search engines used by University undergraduate students in two selected Universities in Ogun and Oyo States, Nigeria.

Ho2: There is no significant relationship between undergraduates in two selected universities and reasons for online search engines' preference.

Ho3: There is no significant difference between undergraduates and level of satisfaction of online search engine usage in two university libraries.

\section{Literature Review}

There is a growing body of research regarding students' Web or databases use in university education [21]. Some online search engines are more used compared to others. There are several search engines being made available to the web. However, the question still remains unanswered why very few of the online search engines are being used. Research has shown that university students and adults face difficulties when searching for information on the Web, while a problem is evaluating search results, and evaluating and selecting sources and information [22].The difficulty in finding specific information on the Web is due to the growth and diversity of information held and the way the information is organized. Although there are several search engines that make Web searches little easier, there are still navigational problems for the students because intelligent search 
strategies are needed to enable them to obtain access to appropriate resources and information [23]. The author stated that "Present day Web browsers and search engines still perform merely the routine actions of a search, leaving the brainwork to the user". [24] in her study on information seeking behavior of final year law student in south western Nigeria University discovered that Google, Wikipedia and Ask.com are the three most popular used information channels with Google taking the lead. The result was obtained from both interview and questionnaire distributed for the purpose of the study. From another study on comparative analysis on six search engines which include three English search engines; Google, Yahoo, MSN and three French search engines; Exalead, Voila and Dir,com [25]. The relevance of search results produced by the search engines using French language was determined. Fourteen first year Students were used for the study. Results from the study showed that Google and Yahoo were the best search engines even though the pass grade was average.

[26] noted that level of awareness of various search engines to students in higher institution is very low. The author further reiterated that students have very confused understanding of various search engines and its concept. More so, many students are not yet involved with various search engines. [27] posits also that the use of the various search engines is very low. At the most basic level undergraduate students lack the existence of the various search engines; many of the students according to Shearer are not familiar with the concept of various search engines. [28] compare the performance of the major search engines Google, Yahoo!, and MSN was found to be the best, with around 90 per cent of queries answered correctly. A survey study carried out by [29] on information technology acceptance by professionals in Delta State University, Nigeria where he used a seven item questionnaire to access the users using search engines. A sample of 211 users of which 201 users completed the survey and response rate was high. He observed that $80(97.95 \%)$ respondents used Google daily, 65 $(74.70 \%)$ respondents used Yahoo 2- 3 times a week, while $14(15.09 \%)$ respondents used Bing once a week. It was also discovered that $12(13.50 \%)$ respondents used Netscape twice a week, $10(11.49 \%)$ respondents use AOL once a month, while $10(11.49 \%)$ respondents used Lycos twice in a month and $10(11.49 \%)$. From the findings, it revealed that many users made more use of Google than other search engines because of the knowledge of Google to them. [30] research result shows that Google is the most used for problem-specific information seeking. The results also show the growing reliance of scientists on general search engines, particularly Google, for finding scholarly articles. In the same vein, [32] study results indicate that the group of users' preferred local Google interface, that is; Google succeeded in its country-specific customization of search results.

In developing countries like Nigeria, it is a major problem towards the use of computer and search engines. [31] opined that the search engine industry in Africa is constrained by low international bandwidth and high dialup tariff, as well as high cost of Personal computers. It has been observed that cost of bandwidth in Africa is much more than that of developed countries. For example, Africa universities, outside South Africa, pay over N55, 000 per Month for $4 \mathrm{mbps}$ in band and $2 \mathrm{mbps}$ out-band width. This amount is about 100 times more expensive than equivalent prices in North American or Europe. [33] asserted that students are faced with the problems of slow Internet connectivity, many sites disappear without any notice or warning, slow access is also barrier, when a large number of simultaneous users are connected to the Internet. [34], conducted a survey on awareness of Internet banking in University of Ibadan Nigeria, to access the search engine students use to have access to the Internet, using the questionnaire as an instrument for data collection. The result reveals that, majority of the students $(64.1 \%)$ of 58 respondents have not heard about other search engines. The most common search engines to them were Google and Yahoo.

According to [35], it is of concern that most students have only a vague understanding of the way search engine works, which resulted in a poor exploitation of their facilities. The potential of the search engine is also currently being limited by relatively slow data transmission speed and by the problems of information management and retrieval posed by the existence of such vast amount of information. [36] posited that information has increasingly come unfiltered. This raised questions about authenticity, validity and reliability. In addition, online information is available through multiple media, including graphical and textual. Users are faced with diverse and abundant information choices, in their studies and workplace. Information seeking involves uncertainty, which decreases as more information is gathered on the search engine. This is a problem, since the quality and aim may vary significantly.

In another study conducted by [37] aimed at knowing the impact of the internet on final year students' research. It was discovered that most of the students used Google $(40 \%)$ as their search engine. The next search engines highly used by students were Yahoo (28\%) and MSN (14\%). Other search engines were used minimally as discovered in the study. [34] conducted a survey on awareness of Internet banking in University of Ibadan Nigeria, to access the search engine students use to have access to the Internet, using the questionnaire as an instrument for data collection. The result reveals that, majority of the students $(64.1 \%)$ of 58 respondents have not heard about other search engines. The most common search engines to them were Google and Yahoo. 


\section{Methodology}

This study adopted a descriptive survey design in order to investigate the types of online search engines used by undergraduate students.

\subsection{Population of the Study}

The population for this study comprised of the undergraduate students of Federal University of Agriculture, Ogun (FUNAAB) and University of Ibadan(UI). The population of undergraduate students in FUNAAB was 14, 199 while that of UI was 13,189 . This totaled to give 27,388 .

\subsection{Sample and Sampling Techniques}

A sample of 151 respondents (students) was drawn from the entire total population of 27, 388 and used for this study. The sample is suitable because [46] suggested that $1 \%$ sample fraction should be used if the population size is above 10,000 . This represents approximately $1 \%$ of the target population of undergraduate students. Proportionate equal allocation method of stratification was used to get the sample size where $1 \%$ was allocated to all the strata irrespective of their weight. This gave the sum of 273 which became the number of undergraduate students that were administered questionnaire. Next, Simple random sampling technique was employed to select five closely faculties from the two universities The faculties that were selected from FUNAAB with their sample size are: Agric Management(16.41), Veterinary Medicine(2.94), Management Science(16.54), Plant Science(31.86) and Animal Science and Livestock Production(23.22). While Agric and Forestry(13.72), Veterinary Medicine(4.46), Sciences(14.56), Clinical Sciences(11.63), and Arts(16.10) were selected from UI. The total sample was 151 .

\section{Figures And Tables}

Data obtained from the study were analyzed using descriptive statistics. Simple percentage, mean and standard deviation were used to analyze the research questions. ANOVA was used for testing hypothesis one, two and three.

TABLE 1: Demographic Variable Analysis

\begin{tabular}{|c|c|c|}
\hline \multirow{2}{*}{\multicolumn{3}{|c|}{$\begin{array}{l}\text { Variables } \\
\text { INSTITUTION }\end{array}$}} \\
\hline & & \\
\hline $\begin{array}{l}\text { Federal University } \text { of } \\
\text { (FUNNAB) }\end{array}$ & 91 & 60.3 \\
\hline University of Ibadan (UI) & 60 & 39.7 \\
\hline Total & 151 & 100.0 \\
\hline GENDER & & \\
\hline Male & 77 & 51.0 \\
\hline Female & 74 & 49.0 \\
\hline Total & 151 & 100.0 \\
\hline AGE & & \\
\hline 16 - 20 years & 54 & 35.8 \\
\hline $21-25$ years & 57 & 37.5 \\
\hline 26 - 30 years & 31 & 20.5 \\
\hline 31 and above years & 9 & 6.0 \\
\hline TOTAL & 151 & 100.0 \\
\hline MARITAL STATUS & & \\
\hline Single & 138 & 91.4 \\
\hline Married & 12 & 7.9 \\
\hline Others & 1 & 0.7 \\
\hline TOTAL & 151 & 100.0 \\
\hline
\end{tabular}

Source: Researcher's Field Work, 2016.

TABLE 1 showed that $91(60.3 \%)$ were undergraduates from federal university of agriculture, Abeokuta. and the remaining $60(39.7 \%)$ of the respondents were undergraduates from university of Ibadan. 77 $(51.0 \%)$ of the respondents were males while the remaining $74(49.0 \%)$ were females. $54(35.8 \%)$ of the respondents are aged between $16-20$ years, $57(37.5 \%)$ are aged between $21-25$ years, $31(20.5 \%)$ are aged between $26-30$ years while $9(6.0 \%)$ are within age 31 years and above. $138(91.4 \%)$ of the respondents are single, $12(7.9 \%)$ are married while $1(0.7 \%)$ belongs to others respectively.

Research Question 1: What are the types of online search engines use by undergraduate students? 
TABLE 2: Types of online search engines used by undergraduate students

\begin{tabular}{|l|l|l|l|l|l|l|l|l|l|}
\hline S/N & TYPES OF ONLINE SEARCH & SA & A & U & D & SD & Mean & STD. D. \\
& ENGINES & & & & & & \\
\hline $\mathbf{1}$ & DuckDuckGo & 1 & 2 & 90 & 31 & 27 & 2.46 & 0.823 \\
& & $0.7 \%$ & $1.3 \%$ & $59.6 \%$ & $20.5 \%$ & $17.9 \%$ & & \\
\hline \multirow{2}{*}{2} & Google & 106 & 18 & 3 & 14 & 10 & 4.30 & 1.269 \\
& & $70.2 \%$ & $11.9 \%$ & $2.0 \%$ & $9.3 \%$ & $6.6 \%$ & & \\
\hline \multirow{2}{*}{3} & Bing & 17 & 34 & 26 & 43 & 31 & 2.75 & 1.316 \\
\hline \multirow{2}{*}{4} & Yahoo & $11.3 \%$ & $22.5 \%$ & $17.2 \%$ & $28.5 \%$ & $20.5 \%$ & & \\
\hline \multirow{2}{*}{5} & Alta Vista & 87 & 25 & 3 & 20 & 16 & 3.97 & 1.447 \\
\hline \multirow{2}{*}{6} & Ask.com (formerly Ask jeeves) & $57.6 \%$ & $16.6 \%$ & $2.0 \%$ & $13.2 \%$ & $10.6 \%$ & & \\
\hline \multirow{2}{*}{7} & Kayak & 4 & 16 & 55 & 38 & 38 & 2.40 & 1.059 \\
\hline \multirow{2}{*}{8} & America Online Launched Search (AOL & $11.3 \%$ & $10.6 \%$ & $36.4 \%$ & $25.2 \%$ & $25.2 \%$ & & \\
& Search) & & 13 & 53 & 20 & 29 & 2.88 & 1.200 \\
\hline
\end{tabular}

Source: Researcher's Field Work, 2016.

TABLE 2 shows that Google with (mean =3.02) was rated highest in the mean score rating on types of online search engines used followed by Yahoo (mean = 3.97), America Online Launched Search (AOL Search) $($ mean $=2.89)$, Ask.com $(2.88)$, Bing 9mean = 2.75), Kayak $($ mean $=2.69)$, DuckDuckGo $($ mean $=2.46)$ and lastly Alta Vista (mean =2.40). "'Fig'" 1 shows the types of online search engines use by undergraduate students in the selected two universities. Where $\mathrm{SA}=$ Strongly Agree, $\mathrm{A}=$ Agree, $\mathrm{D}=$ Disagree and $\mathrm{SD}=\mathrm{Strongly}$ Disagree. $70.2 \%$ and $57.6 \%$ of the respondents strongly agreed that Google and Yahoo were the two types of online search engines mostly used respectively, while $0.7 \%, 11.3 \%, 2.6 \%, 7.3 \%, 0.7 \%$ and $8.6 \%$ strongly agreed that DuckDuckGo, Bingo, Alta Vista, Ask.com, Kayak and America Online Launched Search were also used respectively.

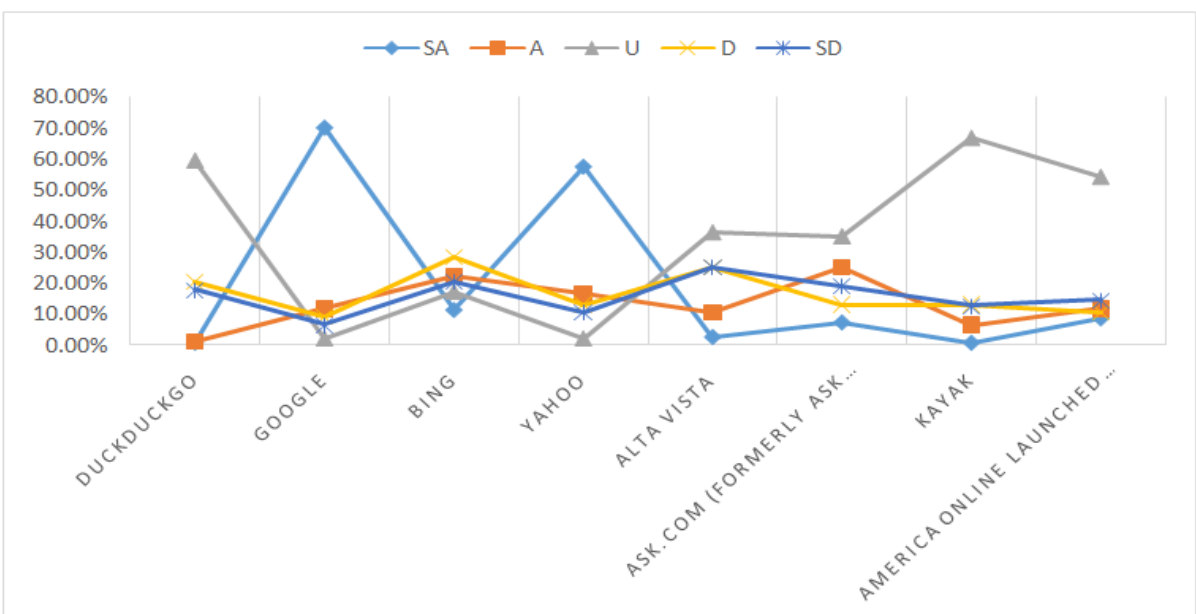

Figure 1: Line graph showing the types of online search engines used by undergraduate students

Research Question 2: How frequently do undergraduate students use online search engines?

TABLE 3: Frequency of use of online search engines by undergraduate students.

\begin{tabular}{|c|c|c|c|c|c|c|c|c|c|}
\hline $\mathbf{S} / \mathbf{N}$ & Items & AFU & MU/FU & RU & NH & NU & DL & Mean & STD. D. \\
\hline 1 & DuckDuckGo & $\begin{array}{l}2 \\
1.3 \%\end{array}$ & $\begin{array}{l}8 \\
5.3 \%\end{array}$ & $\begin{array}{l}39 \\
25.8 \%\end{array}$ & $\begin{array}{l}81 \\
53.6 \%\end{array}$ & $\begin{array}{l}19 \\
12.6 \%\end{array}$ & $\begin{array}{l}2 \\
1.3 \%\end{array}$ & 3.25 & 0.842 \\
\hline 2 & Google & $\begin{array}{l}108 \\
71.5 \%\end{array}$ & $\begin{array}{l}32 \\
21.5 \%\end{array}$ & $\begin{array}{l}7 \\
4.6 \%\end{array}$ & $\begin{array}{l}2 \\
1.3 \%\end{array}$ & $\begin{array}{l}1 \\
0.7 \%\end{array}$ & $\begin{array}{l}1 \\
0.7 \%\end{array}$ & 5.60 & 0.793 \\
\hline 3 & Bing & $\begin{array}{l}14 \\
9.3 \%\end{array}$ & $\begin{array}{l}41 \\
27.2 \%\end{array}$ & $\begin{array}{ll}54 \\
35.8 \%\end{array}$ & $\begin{array}{l}20 \\
13.2 \%\end{array}$ & $\begin{array}{l}13 \\
8.6 \%\end{array}$ & $\begin{array}{l}9 \\
6.0 \%\end{array}$ & 3.97 & 1.291 \\
\hline 4 & Yahoo & $\begin{array}{l}82 \\
54.3 \%\end{array}$ & $\begin{array}{l}35 \\
23.2 \%\end{array}$ & $\begin{array}{l}27 \\
17.9 \%\end{array}$ & $\begin{array}{l}5 \\
3.3 \%\end{array}$ & $\begin{array}{l}1 \\
0.7 \%\end{array}$ & $\begin{array}{l}1 \\
0.7 \%\end{array}$ & 5.25 & 0.981 \\
\hline 5 & $\begin{array}{l}\text { Ask.com(formerly } \\
\text { jeeves) }\end{array}$ & $\begin{array}{l}8 \\
5.3 \%\end{array}$ & $\begin{array}{l}23 \\
15.2 \%\end{array}$ & $\begin{array}{l}51 \\
33.85\end{array}$ & $\begin{array}{l}53 \\
35.1 \%\end{array}$ & $\begin{array}{l}9 \\
6.0 \%\end{array}$ & $\begin{array}{l}7 \\
4.6 \%\end{array}$ & 3.65 & 1.121 \\
\hline 6 & Kayak & $\begin{array}{l}1 \\
0.7 \%\end{array}$ & $\begin{array}{l}9 \\
6.0 \%\end{array}$ & $\begin{array}{l}17 \\
11.3 \%\end{array}$ & $\begin{array}{l}96 \\
63.6 \%\end{array}$ & $\begin{array}{l}22 \\
14.6 \%\end{array}$ & $\begin{array}{l}6 \\
4.0 \%\end{array}$ & 3.03 & 0.848 \\
\hline 7 & $\begin{array}{l}\text { America Online Launched } \\
\text { Search (AOL Search) }\end{array}$ & $\begin{array}{l}9 \\
6.0 \%\end{array}$ & $\begin{array}{l}13 \\
8.6 \%\end{array}$ & $\begin{array}{l}30 \\
19.9 \% \\
\end{array}$ & $\begin{array}{l}72 \\
47.7 \% \\
\end{array}$ & $\begin{array}{l}23 \\
15.2 \%\end{array}$ & $\begin{array}{l}4 \\
2.6 \% \\
\end{array}$ & 3.34 & 1.108 \\
\hline 8 & AltaVista & $\begin{array}{l}5 \\
3.3 \%\end{array}$ & $\begin{array}{l}20 \\
13.2 \%\end{array}$ & $\begin{array}{l}35 \\
23.2 \%\end{array}$ & $\begin{array}{l}54 \\
35.8 \%\end{array}$ & $\begin{array}{l}25 \\
16.6 \%\end{array}$ & $\begin{array}{l}12 \\
7.9 \%\end{array}$ & 3.27 & 1.216 \\
\hline
\end{tabular}


Weighted mean $=3.92$

Source: Researcher's Field Work, 2016.

TABLE 3 reveals Google (mean $=5.60$ ) was rated highest in the mean score rating followed by Yahoo $($ mean $=5.25)$, Bing $($ mean = 3.97), Ask.com (formerly Ask jeeves) $($ mean = 3.65), America Online Launched Search $($ AOL Search) $($ mean $=3.34)$, AltaVista $($ mean $=3.27)$, DuckDuckGo $($ mean = 3.25) and lastly by Kayak (mean $=3.03$ ). TABLE 3 further revealed the weighted mean score of 3.92 out of the maximum 6.00, which is higher than the standard average mean of 3.50. This implies that undergraduate students in the two universities make use of online search engines. 'Fig', 2 shows the frequency of usage of different search engines where ALU = Always Frequently Use, MU/VF = Mostly Use/Very Frequently, RU = Rarely Use, NHI = Never Heard of It, NUI $=$ Never Use It and DLI = Do not Use It. Google was always frequently used search engine with $71.5 \%$ (108) of the respondent agreeing to that. Yahoo was rated second with $54.3 \%$ (82) while 53.6\%, 35.1\%, $63.6 \%$ and $47.7 \%$ of the undergraduate students never heard of DuckDuckGo, Ask.com, Kayak and America Online Launched Search respectively.

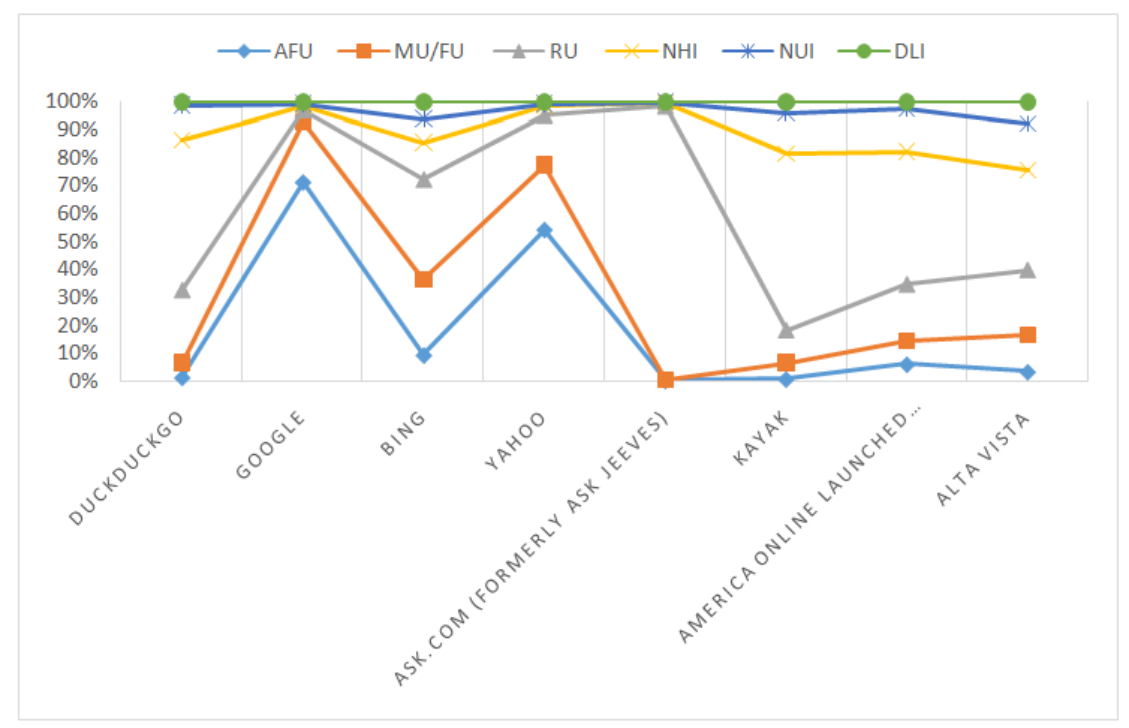

Figure 2: Line graph showing the frequency of use of search engines

Research Question 3: What are the purposes of use of online search engines among undergraduate students in two universities in Ogun and Oyo states?

TABLE 4: Purpose of use of online search engines by undergraduate students

\begin{tabular}{|l|l|l|l|l|l|l|l|}
\hline S/N & Items & SA & A & D & SD & Mean & STD. D \\
\hline 1. & Entertainment (News and Events) & 95 & 41 & 13 & 2 & 3.54 & 0.690 \\
& & $62.9 \%$ & $27.2 \%$ & $8.6 \%$ & 1.3 & \\
\hline 2. & Online shopping & 35 & 100 & 12 & 4 & 3.10 & 0.640 \\
& & $23.2 \%$ & $66.2 \%$ & $7.9 \%$ & $2.6 \%$ & & \\
\hline 3. & Educational purposes (Research, & 120 & 27 & 2 & 2 & 3.77 & 0.531 \\
& Assignments) & $79.5 \%$ & $17.9 \%$ & $1.3 \%$ & $1.3 \%$ & \\
\hline 4. & E-Mailing to family members and friends & 63 & 73 & 8 & 7 & 3.27 & 0.765 \\
& & $41.7 \%$ & $48.3 \%$ & $5.3 \%$ & 4.65 & & \\
\hline 5. & Discussion forum/communication & 67 & 60 & 18 & 6 & 3.27 & 0.810 \\
& & $44.7 \%$ & $39.3 \%$ & $12.0 \%$ & $4.0 \%$ & \\
\hline 6. & Social networking & 77 & 59 & 10 & 5 & 3.65 & 0.854 \\
& & 51.0 & $39.1 \%$ & $6.6 \%$ & $3.3 \%$ & \\
\hline
\end{tabular}

Source: Researcher's Field Work, 2016.

TABLE 4 indicates the purposes of use of online search engines by undergraduate students. Educational purposes (research, assignments) (mean $=3.77$ ) was rated highest in the mean score rating followed by social networking (mean = 3.65), Entertainment (News and Events) (mean = 3.54), E-Mailing to family members and friends and Discussion forum/communication (mean = 3.27) and lastly by Online shopping (mean = 3.10). Table 7 further revealed that respondents mostly used online search engines for educational purpose either for research or assignment, followed by social networking and least used it for online shopping. 
Research Question 4: What is the level of satisfaction of online search engines use?

TABLE 5: Level of satisfaction of online search engines use

\begin{tabular}{|l|l|l|l|l|l|l|l|}
\hline S/N & Item & VS & S & FS & D & Mean & STD. D \\
\hline 1. & Level of Satisfaction of search engine Use & 51 & 76 & 22 & 2 & 3.17 & 0.716 \\
& & $33.8 \%$ & $50.3 \%$ & $14.6 \%$ & $1.3 \%$ & & \\
\hline
\end{tabular}

Source: Researcher's Field Work, 2016.

TABLE 5 shows that $51(33.8 \%)$ of undergraduate students were very satisfied with the use of online search engines; 76(50.3\%) were satisfied; 22(14.6\%) were fairly satisfied while 2(1.3\%) were dissatisfied. Furthermore, the TABLE revealed the mean score of 3.17 out of the maximum 4.00 , which is higher than the standard mean of 2.50. This implies that the undergraduate students were satisfied with the use of online search engines.

Research Question 5: What are the reasons that influence undergraduate students search engines' preference/likeness?

TABLE 6: Reasons that influence undergraduate students search engine preference/likeness

\begin{tabular}{|c|c|c|c|c|c|c|c|}
\hline $\mathrm{S} / \mathrm{N}$ & Items & SA & $\mathrm{A}$ & $\mathrm{D}$ & SD & Mean & STD. D \\
\hline 1. & Home page style & $\begin{array}{l}80 \\
53.0 \%\end{array}$ & $\begin{array}{l}46 \\
30.5 \%\end{array}$ & $\begin{array}{l}23 \\
15.2 \%\end{array}$ & $\begin{array}{l}2 \\
1.3 \%\end{array}$ & 3.35 & 0.785 \\
\hline 2. & Relevantly ranked result order & $\begin{array}{l}40 \\
26.5 \%\end{array}$ & $\begin{array}{l}94 \\
62.2 \%\end{array}$ & $\begin{array}{l}16 \\
10.6 \%\end{array}$ & $\begin{array}{l}1 \\
0.7 \%\end{array}$ & 3.34 & 0.506 \\
\hline 3. & Quantity of retrieved results during browsing & $\begin{array}{l}78 \\
51.7 \%\end{array}$ & $\begin{array}{l}60 \\
39.7 \% \\
\end{array}$ & $\begin{array}{l}9 \\
6.0 \% \\
\end{array}$ & $\begin{array}{l}4 \\
2.6 \% \\
\end{array}$ & 3.40 & 0.723 \\
\hline 4. & Popularity of search engines & $\begin{array}{l}60 \\
39.7 \%\end{array}$ & $\begin{array}{l}75 \\
49.7 \%\end{array}$ & $\begin{array}{l}14 \\
9.3 \% \\
\end{array}$ & $\begin{array}{l}2 \\
1.3 \% \\
\end{array}$ & 3.28 & 0.685 \\
\hline 5. & Easy user interface & $\begin{array}{l}76 \\
50.3 \%\end{array}$ & $\begin{array}{l}67 \\
44.4 \%\end{array}$ & $\begin{array}{l}5 \\
3.3 \% \\
\end{array}$ & $\begin{array}{l}3 \\
2.0 \% \\
\end{array}$ & 3.43 & 0.658 \\
\hline 6. & Helpful options to broaden or narrow a search & $\begin{array}{l}70 \\
46.4 \%\end{array}$ & $\begin{array}{l}71 \\
47.0 \%\end{array}$ & $\begin{array}{l}6 \\
4.0 \%\end{array}$ & $\begin{array}{l}1 \\
0.7 \%\end{array}$ & 3.37 & 0.689 \\
\hline 7. & Spell checker that corrects errors & $\begin{array}{l}59 \\
39.1 \%\end{array}$ & $\begin{array}{l}72 \\
47.7 \%\end{array}$ & $\begin{array}{l}19 \\
12.5 \%\end{array}$ & $\begin{array}{l}1 \\
0.7 \%\end{array}$ & 3.29 & 0.708 \\
\hline 8. & Speed of response of search engines is good & $\begin{array}{l}40 \\
26.5 \%\end{array}$ & $\begin{array}{l}94 \\
62.2 \%\end{array}$ & $\begin{array}{l}16 \\
10.6 \%\end{array}$ & $\begin{array}{l}1 \\
0.7 \%\end{array}$ & 3.34 & 0.506 \\
\hline 9. & Search engines have E-Mail support & $\begin{array}{l}79 \\
52.3 \%\end{array}$ & $\begin{array}{l}61 \\
40.4 \%\end{array}$ & $\begin{array}{l}9 \\
6.0 \%\end{array}$ & $\begin{array}{l}2 \\
1.3 \%\end{array}$ & 3.57 & 0.896 \\
\hline 10. & The language used is very simple and clear & $\begin{array}{l}78 \\
51.7 \%\end{array}$ & $\begin{array}{l}60 \\
39.7 \% \\
\end{array}$ & $\begin{array}{l}9 \\
6.0 \% \\
\end{array}$ & $\begin{array}{l}4 \\
2.6 \% \\
\end{array}$ & 3.40 & 0.723 \\
\hline 11. & $\begin{array}{l}\text { Information are always updated on search } \\
\text { engines }\end{array}$ & $\begin{array}{ll}60 \\
39.7 \%\end{array}$ & $\begin{array}{l}75 \\
49.7 \%\end{array}$ & $\begin{array}{l}14 \\
9.3 \%\end{array}$ & $\begin{array}{ll}2 \\
1.3 \%\end{array}$ & 3.28 & 0.685 \\
\hline
\end{tabular}

Source: Researcher's Field Work, 2016.

TABLE 6 shows that search engines have E-Mail support (mean = 3.57) was rated highest in the mean score rating followed by Easy user interface (mean $=3.43$ ), Quantity of retrieved results during browsing and the language used is very simple and clear (mean $=3.40)$, Helpful options to broaden or narrow a search $($ mean $=$ 3.37), Home page style (mean $=3.35$ ), Relevantly ranked result order and Speed of response of search engines is good $($ mean $=3.34)$, Spell checker that corrects errors $($ mean $=3.29)$ and lastly by Popularity of search engines and Information are always updated on search engines (mean = 3.28). TABLE 6 further revealed that the respondents were highly influenced by search engines that have support for E-mail, followed by easy user interface and were least influenced by the popularity of search engines and up datedness of information on search engines.

Research Question 6: What are the general opinions of university undergraduate students on online search engines challenges?

TABLE 7: Opinions of undergraduate students on online search engines challenges

\begin{tabular}{|l|l|l|l|l|l|l|l|l|}
\hline S/N & Statements & SA & A & U & D & SD & Mean & STD.D \\
\hline 1. & Too many information are released during & 95 & 41 & 10 & 4 & 1 & 4.49 & 0.790 \\
& browsing & $62.9 \%$ & $27.2 \%$ & $6.6 \%$ & $2.6 \%$ & $0.7 \%$ & & \\
\hline 2. & Discomfort from Advertisements during browsing & 23 & 86 & 27 & 11 & 4 & 3.75 & 0.896 \\
& & $15.2 \%$ & $57.0 \%$ & $17.9 \%$ & $7.3 \%$ & $2.6 \%$ & & \\
\hline 3. & Some results released are irrelevant & 49 & 55 & 37 & 9 & 1 & 3.94 & 0.933 \\
& & $32.5 \%$ & $36.4 \%$ & $24.5 \%$ & $6.0 \%$ & $0.7 \%$ & & \\
\hline 4. & Poor network connectivity & 70 & 52 & 18 & 9 & 2 & 4.18 & 0.955 \\
& & $46.4 \%$ & $34.4 \%$ & $11.9 \%$ & $6.0 \%$ & $1.3 \%$ & & \\
\hline 5. & Using search engines is expensive & 41 & 73 & 26 & 11 & - & 3.95 & 0.859 \\
\hline
\end{tabular}


Online Search Engines Used By Undergraduate Students In Two Selected University In Ogun And Oyo

\begin{tabular}{|c|c|c|c|c|c|c|c|c|}
\hline & & $27.2 \%$ & $48.3 \%$ & $17.2 \%$ & $7.3 \%$ & - & & \\
\hline 6. & Takes too long to download pages & $\begin{array}{l}70 \\
46.4 \%\end{array}$ & $\begin{array}{l}63 \\
41.7 \%\end{array}$ & $\begin{array}{l}15 \\
9.9 \%\end{array}$ & $\begin{array}{l}3 \\
2.0 \%\end{array}$ & - & 4.32 & 0.735 \\
\hline 7. & Hacking of personal information by online thieves & $\begin{array}{l}73 \\
48.3 \% \\
\end{array}$ & $\begin{array}{l}62 \\
41.1 \% \\
\end{array}$ & $\begin{array}{l}11 \\
7.3 \% \\
\end{array}$ & $\begin{array}{l}3 \\
2.05 \\
\end{array}$ & $\begin{array}{l}2 \\
1.3 \% \\
\end{array}$ & 4.33 & 0.806 \\
\hline
\end{tabular}

Source: Researcher's Field Work, 2016.

TABLE 7 depicts that too many information are released during browsing $($ mean $=4.49)$ was rated highest in the mean score rating followed by Hacking of personal information by online thieves (mean $=4.33$ ), Takes too long to download pages $($ mean $=4.32)$, Poor network connectivity $($ mean $=4.18)$, Using search engines is expensive (mean $=3.95)$, Some results released are irrelevant (mean $=3.94)$ and lastly by Discomfort from Advertisements during browsing (mean $=3.75$ ). The TABLE further revealed that the respondents were mostly challenged by too many information released during browsing, followed by hacking of personal information by online thieves and were less challenged by discomfort from Advertisements during browsing.

Research Question 7: What are the undergraduate students' suggestions on improving online search engines use?

TABLE 8: Suggestions on improving Online search engines

\begin{tabular}{|l|l|l|l|l|l|l|l|}
\hline S/N & WAYS OF IMPROVING SEARCH ENGINES & SA & A & D & SD & Mean & STD.D \\
\hline 1. & Reduce information overload during browsing & 117 & 29 & 2 & 3 & 3.75 & 0.556 \\
& & $77.5 \%$ & $19.2 \%$ & $1.3 \%$ & $2.0 \%$ & \\
\hline 2. & Reduce the amount of Advertisements released & 74 & 63 & 10 & 4 & 3.37 & 0.727 \\
& & $49.0 \%$ & $41.7 \%$ & $6.6 \%$ & $2.6 \%$ & & \\
\hline 3. & Only relevant results should be displayed & 89 & 49 & 9 & 3 & 3.52 & 0.683 \\
& & $59.3 \%$ & $32.7 \%$ & $6.0 \%$ & $2.0 \%$ & \\
\hline 4. & Provide search engines with high bandwidth & 57 & 77 & 16 & 1 & 3.26 & 0.668 \\
& & $37.7 \%$ & 51.05 & $10.6 \%$ & $0.7 \%$ & & \\
\hline 5. & Reduce cost of using search engines for students & 102 & 47 & 1 & 1 & 3.66 & 0.530 \\
& & $67.5 \%$ & $31.1 \%$ & $0.7 \%$ & $0.7 \%$ & \\
\hline 6. & Speed up time to download pages & 78 & 57 & 12 & 4 & 3.41 & 0.733 \\
& & $51.7 \%$ & $37.7 \%$ & $7.9 \%$ & $2.6 \%$ & \\
\hline 7 & Mega Protect sensitive information from hackers & 54 & 70 & 20 & 7 & 3.15 & 0.828 \\
& & $35.8 \%$ & $46.4 \%$ & $13.2 \%$ & $4.6 \%$ & \\
\hline
\end{tabular}

Source: Researcher's Field Work, 2016.

TABLE 8 indicates Reduce information overload during browsing (mean $=3.75$ ) was rated highest in the mean score rating followed by Reduce cost of using search engines for students (mean $=3.66$ ), Only relevant results should be displayed (mean $=3.52$ ), Speed up time to download pages (mean $=3.41$ ), Reduce the amount of Advertisements released (mean $=3.37$ ), Provide search engines with high bandwidth (mean $=3.26$ ) and lastly by Protect sensitive information from hackers $($ mean $=3.15$ ). Furthermore, it was revealed that the respondents mostly suggested the reduction of information overload during browsing followed by reduction in the cost of using search engines for students and least suggested protection of sensitive information from hackers would help improve the use of online search engines.

\section{Testing of Hypotheses}

Ho1: There is no significant difference between types of Online Search engines used by undergraduate students in two selected Universities in Ogun and Oyo States, Nigeria

TABLE 9: types of Online Search Engines used among University undergraduate students in two selected Universities

\begin{tabular}{|l|l|l|l|l|l|l|l|}
\hline Variable & $\mathrm{N}$ & Mean & Std. Dev. & df & $\mathrm{t}$ & P-value & Remark \\
\hline University of Ibadan & 60 & 20.96 & 4.03 & & & N.S \\
$\begin{array}{l}\text { Federal university of Agriculture } \\
\text { (FUNNAB) }\end{array}$ & 91 & 21.91 & 2.83 & 148 & -1.664 & .098 & N. \\
\hline
\end{tabular}

N. S denotes not significant at $\mathrm{P}<.05$

TABLE 9 shows that there was no significant difference between types of online search engines used by university undergraduate students in two selected universities in Ogun and Oyo States $(\mathrm{t}=-1.664$, $\mathrm{df}=148$, $\mathrm{P}>$.05). Hence, the null hypothesis 1 was not rejected but accepted.

Ho2: There is no significant relationship between undergraduates in two selected universities and reasons for online search engines preference. 
TABLE 10: Relationship between undergraduates in two selected universities and reasons for online search engine preference

\begin{tabular}{|l|l|l|l|l|l|l|l|}
\hline Variable & $\mathrm{N}$ & Mean & Std. Dev. & df & r & P-value & Remark \\
\hline University of Ibadan & 60 & 22.41 & 3.05 & & \multirow{2}{*}{0.286} & $.000^{*}$ & Sig. \\
Federal university of Agriculture (FUNNAB) & 91 & 24.53 & 4.02 & & & \\
\hline
\end{tabular}

* denotes significant at $\mathrm{P}<.05$

TABLE 10 shows that there was a positive, low significant relationship between undergraduate students in two selected universities and reasons for online search engine preference $(r=0.286 ; \mathrm{P}<.05)$. Hence, the null hypothesis was rejected.

Ho3: There is no significant difference between undergraduates and level of satisfaction of online search engine usage in two selected universities.

TABLE 11: Difference between undergraduates and level of satisfaction of online search engines' usage in two selected universities.

\begin{tabular}{|l|l|l|l|l|l|l|l|}
\hline Variable & $\mathrm{N}$ & Mean & Std. Dev. & df & t & P-value & Remark \\
\hline University of Ibadan & 60 & 3.01 & 0.65 & & \multirow{2}{*}{. } & \multirow{2}{*}{ Sig. } \\
Federal university of Agriculture (FUNNAB) & 91 & 3.32 & 0.76 & & \\
\hline
\end{tabular}

* denotes significant at $\mathrm{P}<.05$

TABLE 11 shows that there was significant difference between undergraduates and level of satisfaction of online search engine usage in two university libraries $(\mathrm{t}=2.668 ; \mathrm{P}<.05)$. Hence, the null hypothesis was rejected.

\section{Discussion}

The findings on the demographic variables on TABLE 1 showed that $91(60.3 \%)$ were undergraduates from Federal University of Agriculture, Abeokuta. and the remaining 60 (39.7\%) of the respondents were undergraduate students from University of Ibadan. $77(51.0 \%)$ of the respondents were males while the remaining $74(49.0 \%)$ were females. This implies that more males used the online search engines more than their female counterpart. $54(35.8 \%)$ of the respondents are aged between 16 - 20 years, $57(37.5 \%)$ are aged between 21 - 25 years, $31(20.5 \%)$ are aged between 26 - 30 years while $9(6.0 \%)$ are within age 31 years and above. Large number of the undergraduate students who used the online search engines in the two selected universities was in the age interval of 21-25 years. $138(91.4 \%)$ of the respondents are single, $12(7.9 \%)$ are married while $1(0.7 \%)$ belongs to others respectively.

The finding on types of search engines used by undergraduate students as presented on TABLE 2 indicated that Google had the highest mean of 4.30 was rated highest followed by Yahoo with mean of 3.9. The other search engines were also identified with their mean. They include: America Online Launched Search (AOL Search) $($ mean $=2.89)$, Ask.com $(2.88)$, Bing 9mean $=2.75)$, Kayak $($ mean $=2.69)$, DuckDuckGo $($ mean $=2.46)$ and lastly by Alta Vista (mean $=2.40$ ) were indicated. This conforms to the research of [38] on Awareness, Use and Impediments of Search Engines by Undergraduate Students in Delta State University, Abraka-Nigeria where they found that undergraduate students have low awareness of the other major search engines apart from Yahoo and Google.

According to the findings on TABLE 3, Google was always frequently used search engine with $71.5 \%$ (108) of the respondent indicated that. This situation makes Google the most famous search engine for students in this research. Yahoo was rated second with 54.3\% (82). Another finding in the study revealed that few proportion of the respondents indicated that they do not like the other search engines as shown by their respective responses. 2(1.3\%), $1(0.7 \%), 9(6.0 \%), 1(0.7 \%), 7(4.6 \%), 6(4.0 \%), 4(2.6 \%)$, and 12(7.9\%) of the respondents don't like DuckDuckGo, Google, Bing, Yahoo, Alta Vista, Ask.com (formerly Ask jeeves), Kayak and America Online Launched Search (AOL Search). This calls for awareness creation on the other search engines. The table further revealed the weighted mean score of 3.92 out of the maximum 6.00 , which is higher than the standard average mean of 3.50. This implies that undergraduate students in the two universities make use of online search engines. $53.6 \%, 35.1 \%, 63.6 \%$ and $47.7 \%$ of the undergraduate students never heard of DuckDuckGo, Ask.com, Kayak and America Online Launched Search respectively. This contradicts the research result of [18] that carried out a comparative study on three search engines to know which best meet users need. They found that Yahoo obtained the highest results among the three Web search engines tested. This was followed by Google and ask.com. However, the result of this present which reveals that Google is the most frequently used search engine while others have never been heard of or used is in line with the findings of the study by [39] on the use of search engines by post graduate students. She discovered that most post graduate students are only exposed to Google and Yahoo search engines. Further result indicated that many of the students are not very much exposed or even aware of any other various search engines available on the Internet. It also corroborates with the work of [40] who affirmed that today, Google is working as primary information resource of internet users. On the whole, It 
could be seen that greater number of the online search engines were not frequently used by the undergraduate students.

The purposes of use of online search engines by undergraduate students as presented in TABLE 4 revealed that respondents mostly used online search engines for educational purpose either for research or assignment, followed by social networking and least used it for online shopping. This is evident in the mean score; Educational purposes (research, assignments) (mean $=3.77$ ) was rated highest in the mean score rating followed by social networking (mean $=3.65)$ and lastly by Online shopping $($ mean $=3.10)$. This agrees with the research of [41] who opined that undergraduate students are often asked to search for information online in order to complete their university assignments and they are also searching the Web for personal purposes. TABLE 5 shows that $51(33.8 \%)$ of undergraduate students were very satisfied with the use of online search engines; $76(50.3 \%)$ were satisfied; 22(14.6\%) were fairly satisfied while 2(1.3\%) were dissatisfied. Furthermore, the mean score of 3.17 out of the maximum 4.00, which is higher than the standard mean of 2.50 , was also revealed. This implies that the undergraduate students were satisfied with the use of online search engines. Undergraduate students believe and rely in the results displayed by these online search engines not minding the source and accuracy of the information. This conforms to the finding of [42] who noted that it astonishes to what degree users trust search engines and they rely on Web search engines to display the most credible results first.

As seen in TABLE 6, of all the items listed to influence undergraduate students' preference for search engines, the most important criterion is that search engines have E-Mail support (mean = 3.57) followed by Easy user interface (mean $=3.43$ ), Quantity of retrieved results during browsing and the language used is very simple and clear (mean $=3.40)$, Helpful options to broaden or narrow a search $($ mean $=3.37)$, Home page style $($ mean $=$ $3.35)$, Relevantly ranked result order and Speed of response of search engines is good $(\operatorname{mean}=3.34)$, Spell checker that corrects errors (mean $=3.29$ ) and lastly by Popularity of search engines and Information are always updated on search engines (mean $=3.28$ ). These findings revealed that the respondents were highly influenced by search engines that have support for E-mail, followed by easy user interface and were least influenced by the popularity of search engines and up datedness of information on search engines. This agrees with the research result of [43] who conducted a study to know the most popular search engines among students of Near East University, Cyprus. They found out that the most important criterion for students that influence them for search engine preferring is number of correct results with $62 \%$ frequency, number of results has $44 \%$ frequency, user interface has $40 \%$ frequency, result page style for $23.30 \%$ of students, $18.70 \%$ gives importance of page style and popularity of search engines has the lowest important criterion with $18.30 \%$ frequency for students.

Undergraduate students are faced with numerous problems from the use of search engines, and one major problem which they face is the problem of too many information are released during browsing. This is revealed in TABLE 7. The TABLE further revealed that students were less challenged by discomfort from Advertisements during browsing. This moderately agrees with the findings of [43] who noted that students were satisfied with the speed of their favorite search engine with a total of $88.33 \%$. The authors further added that nearly all search engines publish some advertisements, especially on the result page. However, students evaluated the published advertisement on search engines and $65.67 \%$ of them underlined that advertisements bother them. $61 \%$ of students feel that their favorite search engine is updated daily. Also $92.33 \%$ of students are satisfied from language support of their favorite search engine. $75.67 \%$ of students use e-mail support of their favorite search engine. 55\% of students need to see enough results at the end of their searches. Emphasizing of keywords helps $46.67 \%$ of students and $2.33 \%$ of students complains about retrieved irrelevant results during search process

Large proportion of undergraduate students with $($ mean $=3.75)$ indicated reduce information overload during browsing as a way of improving online search engines. They also suggested reduce cost of using search engines for students $($ mean $=3.66)$, only relevant results should be displayed $($ mean $=3.52)$, Speed up time to download pages $($ mean $=3.41$ ), Reduce the amount of Advertisements released (mean $=3.37$ ), Provide search engines with high bandwidth (mean $=3.26)$ and lastly by Protect sensitive information from hackers $($ mean $=$ 3.15). As seen in TABLE 8, the respondents seen to contradict the opinions on ways of improving online search as they didn't rank the items in the way they did for the challenges. For example, discomfort from advertisements had the least mean as a challenge but now seen as an important suggestion to improving online search engines. The above findings conform to the research of [44] that carried out a comparative study on some popular websites so as to determine their effectiveness based on its content, response time. The study was based on measures such as search output quantity, search time, relevant documents retrieved, search precision and the quantity of African contents in the search. It was discovered that Google, MSN and Yahoo search engines have high document quantity retrieval capacity with low response time but their effectiveness (precision) in retrieving relevant documents is very low. Also, it was discovered that they are good avenues for advertisement on the site. The study concluded that, though a Web search engine is very popular and able to retrieve large number of documents. That does not mean that it has high precision for retrieving relevant documents for its users. 
The result for hypothesis one as presented in TABLE 9 revealed that there was no significant difference between types of Online search engines used by undergraduate students in two selected Universities in Ogun and Oyo States, Nigeria Hence, the null hypothesis was not rejected but accepted since the difference in their mean is negligible. This agrees to the finding of [45] when she conducted a survey on five major search engines (Google, Yahoo!, MSN, Seekport and Ask.com) to know their retrieval effectiveness. It was discovered that Google and Yahoo performed best and there was no significant differences between them. The result for hypothesis two as shown in TABLE 10 revealed that there was a positive, low significant relationship between undergraduate students in two selected universities and reasons for online search engine preference. Hence, the null hypothesis was rejected. This implies that the undergraduate students depend and make frequent use of the major search engines known to them. The result for hypothesis three in TABLE 11 showed that there was significant difference between undergraduates and level of satisfaction of online search engine usage in two universities. Hence, the null hypothesis was therefore rejected. This could mean that undergraduate students were satisfied with the use of search engines.

\section{Conclusion}

The foremost observation is that online search engines be structure better so that undergraduate students can easily retrieve relevant documents of their choice for educational and personal purposes. The findings of this study have shown that Google is the most frequently used online search engine followed by Yahoo. Undergraduate students were not exposed to the other major search engines apart from Google and Yahoo. Furthermore, some of the online search engines had never been heard of; some were not used while some were dislike by the undergraduate students. By implications, frequently used ones witnessed congestion at their sites leaving out the poorly used ones.

These findings provide a foundation for a further research study to examine undergraduate students' responses for a required online assessment on their own work settings and recording using the other online search engines that they are unaware of. Such an extension will seek to confirm and build upon the findings of this research and add to the knowledge base about online searching by providing a better insight into the structure of online search engines as regarding how they are assessed by students as information retrieval tools. There is therefore an urgent call for user education through practical demonstration and orientation so as to help increase knowledge of the other few used online search engines.

\section{Recommendation}

Recommendations are made based on the findings of this study as follows:

1. Librarians should provide knowledge about different online search engines to undergraduate students and not just Google and Yahoo.

2. Webmasters should advertise the other online search engines online so as to increase knowledge and patronage to them.

3. Relevant information should be displayed only during browsing.

4. Webmaster should consider enhancing the speed it would take to download results.

\section{Acknowledgement}

First and foremost, i would like to thank God Almighty for blessing me with the strength, wisdom and courage to finish this research. I am thankful and would like to express my sincere gratitude to Mr. Crescent for his guidance, support and continuous encouragement in making this study possible. My sincere thanks to Prof. Ochai, Dr. Akintunde, Dr. Abubakar, my family and friends in the likes of Mrs. Nwokedi, Mrs. Mairo, Mrs. Panyi, Mrs. Agaku, Mrs. Bukla and all those who helped me in many ways, gave valuable advises and made this journey easy.

\section{Reference}

[1] W. Hu, Y. Chen, M. Schmalz, M. and G.X. Ritter, An Overview of World Wide Web Search Technologies. Auburn University, University of Florida, USA.

[2] Batzios, A., C. Dimou, A.L.Symeonidis, and P.A. Mitkas, BioCrawler: An Intelligent Crawler for the Semantic Web, Expert Systems with Applications, 53 (1/2), 524-530.

[3] K. Paul, Major search engines available, international year book of library and information management scholarly publishing in an electronic era,. Journal of Information Science. 23(3), 2014, $200-225$.

[4] C. Louis, How to stop searching and start finding P.C. world. Retrieved from http://ucla.edu/pdf/ searches/paper michaels.pdf 10(8), 2012, 24-28.

[5] A. Large, and H. Moukdad, "Multilingual access to web resources: an overview", Program, electronic library and information systems, $34(1), 2000,, .43-58$.

[6] D. Dudek, and A. Mastora, and M. Landoni, "Is Google the answer? A study into usability of search engines", Library Review, 2007, 56 Iss: $3, .224-233$.

[7] B. Duke, The perceived affordance of web search engines. A comparative analysis. Sils technical report, 2010.

[8] D. Sullivan, Nielsen / NetRatings search engine ratings, Retrieved March 10, 2008, from http://www.searchenginewatch.com/reports/netratings.html. 
[9] J. Zhang, and S. Lin, "Multiple language supports in search engines", Online Information Review, 31(4), 2007,516 - 532.

[10] [10] Y. Hong, and K. David., "A Cognitive Evaluation of Four Online Search Engines For Answering Definitional Questions Posed By Physicians." Pacific Symposium on Biocomputing, 12, 2007, 328-339.

[11] A. Jonan, Access to electronic information and information research. Worcester, mass: Clark university press, 2010, $209-31$.

[12] J. Maxymuk, "No search limits", Bottom Line: Managing Library Finances, the, 21 (4), 2008,132 - 134.

[13] T. Taiwo, Self awareness its nature and development. New York, N.V. Guilford presses, 2009.

[14] O. Lindary, O. and P. Mclaren, Advantages and Disadvantages of online searches, Retrieved from http://www.elseervier.com/ locate/compedu 2010.

[15] R. Kandell, Computer use among college students, An exploratory study, Journal of America College Health, 50(1), 2012, 21-26.

[16] B. J. Jansen, and A. Spink, How are we searching the World Wide Web? A comparison of

[17] nine search engine transaction logs, Elsevier Ltd, Information Processing and Management, 42, $2006,248-263$.

[18] Alexa Internet Inc., Top sites United States, Retrieved March 10, 2008 from http://www.alexa.com/site/ds/top_sites?cc=US\&ts_mode=country\&lang=none

[19] U.U. Abraham and J.K. Alhassan, "Comparative Study on Three Major Internet Search Engines," Information Technologist 5 (2), 2011.

[20] P. Kristen "Search and Email Still Top the List of Most Popular Online Activities. Pew Internet. at http://pewinternet.org/Reports/2012/Search-Engine-Use-2012/Main-find accessed 10 September, 2013.

[21] N.N. Margeret. "Use of Search Engines by Postgraduate Students of the University" Journal of Computer Engineering (IOSRJCE), 3(2), 2012, 30-40.

[22] R. Boella,. Press release: Google, Yahoo!, apple and Microsoft most talked about brands online, Retrieved March 1, 2008, from http://www.e consultancy.com/news-blog/363695/googleyahoo-apple-and- microsoft-most-talked-about-brands-online.htmle (2007).

[23] Y. Bitirim, Y. Tonta, and H. Sever, H, Türkçe Arama Motorlarında Performans Değerlendirme, Damla Matbaası, Turkey, 2002.

[24] M. Shanahan,Transforming information search and evaluation practices of undergraduate students, International Journal of Medical

[25] Informatics, 77(8), 2008, 518- 526.

[26] S. Brand- Gruwel, L. Wopereis, and Y. Vermetten, Information problem solving: Analysis of a complex cognitive skill, Computers in Human Behavior, 21(3), 2005, 487-508.

[27] A. Lazonder, Exploring novice users' training needs in searching information on the Web. Journal of Computer Assisted Learning, 16(4), 2000, 326- 335 .

[28] O.C. Onwuchukwa, "Information Seeking Behaviour of Final Year Law Students in South West Nigeria University", Information and Knowledge Management, 3(5), 2013, At http://www.iiste.org accessed 15 September, 2013

[29] J. Véronis, "The Comparative Study of Six Search Engines", At : http://sites.univ-provence.fr/veronis/pdf/2006-comparativestudy.pdf accessed 1 September, 2014

[30] B. Adams, The cautions faculty: their awareness and attitude towards institutional repositories. Malaysian Journal of Library and Information Science. 14(2), 2010, 17-39.

[31] R. Shearer, Worldwide awareness searches: towards the identification of critical success factors. Canadian Journal of Information Science. 44(12), 2012, 20-23.

[32] D. Lewandowski, "The retrieval effectiveness of search engines on navigational queries", Aslib Proc, 63 (4), 2011,354 - 363.

[33] R. Joe, Information technology acceptance by professionals. Journal of information science, 6(10), 2011, 65-67.

[34] H. Jamali, and H. Asadi, "Google and the scholar: the role of Google in scientists' information-seeking behavior", Online Information Review, 34 (2), 2010, $282-294$.

[35] E.A, Adogbeji, Times flies when you're having fun: cognitive absorption and beliefs about information technology usage. MIS. Quarterly 24, 2005.

[36] J. Bar-Ilan, and Levene, M. “A method to assess search engine results”, Online Information Review, 35 (6 ), 2011,854 - 868.

[37] J. Amoritpal, University students' perception of the Internet. An explorative study. Journal of Academic Librarianship, 25(7), 2000, $456-461$.

[38] B. Colley, Awareness of internet banking in university, Journal of Emerging Trends in Computing and Information Sciences, 6(12), 2011.

[39] A. Gellieb, Search engine types. Retrieved from http://wwwbuzzle.com/articles/search engine, and types, 2013.

[40] M. Ganzha, M. Paprzycki, and J. Stadnik, Combining Information from Multiple Search Engines-Preliminary Comparison. Information Science, 180(10), 2010, 1908- 1923.

[41] C. Levin, The impact of information technology on Greek academic libraries and libraries: A preliminary result in Aparas. Educational Research, 50 (6), 2002, 191-200.

[42] I. I.Promise and I. Goodluck, "Impact of the Internet on Final Year Students research: A Case of Covenant University Ota Nigeria," Library Philosophy, 2010, 403, at http://digital commons.unl.edu/ libphilprac/403 accessed 15 August, 2014.

[43] A. Daniel and J. P. Oghale, Awareness, Use and Impediments of Search Engines by Undergraduate Students in Delta State University, Abraka-Nigeria. Journal of Emerging Trends in Computing and Information Sciences. 6(12), 2014.

[44] N.N. Margeret. "Use of Search Engines by Postgraduate Students of the University", Journal of Computer Engineering (IOSRJCE), $3(2), 2012,30-40$.

[45] B. Detlor, and V. Lewis, Academic library Web sites: Current practice and future directions. The Journal of Academic Librarianship, 32(3), 2006, 251- 258.

[46] E. Hargittai, L. Fullerton, E. Menchen-Trevino, and K.Y.Thomas, Trust online: Young adults' evaluation of Web content. International Journal of Communication, 4, 2010, 468-494.

[47] C. Nadire and A. Kezban. "Which Search Engine Is The Most Used One Among University Students “ The Online Journal of Science and Technology, 1, 2011, At http://ww.ojst.com accessed 15 September, 2013

[48] S.O Akinola. "Comparative Study of Some Popular Web Search Engines". African Journal of Computing \& ICT, 3(1), 2010.

[49] P. Kristen, "Search and Email Still Top the List of Most Popular Online Activities, Pew Internet. at http://pewinternet.org/Reports/2012/Search-Engine-Use-2012/Main-find accessed 10 September, 2013.

[50] J. Curry "Rule of thumb on sampling techniques, 1984.

Judith Odanwu Ogbole. "Online Search Engines Used By Undergraduate Students In Two Selected University In Ogun And Oyo States, Nigeria." IOSR Journal of Research \& Method in Education (IOSR-JRME) 7.4 (2017): 01-13. 